\title{
Semicompatibilism and Moral Responsibility for Actions and Omissions: In Defense of Symmetrical Requirements
}

\author{
Taylor W. Cyr
}

Forthcoming in Australasian Journal of Philosophy; please cite published version.

\begin{abstract}
Although convinced by Frankfurt-style cases that moral responsibility does not require the ability to do otherwise, semicompatibilists have not wanted to accept a parallel claim about moral responsibility for omissions, and so they have accepted asymmetrical requirements on moral responsibility for actions and omissions. In previous work, I have presented a challenge to various attempts at defending this asymmetry. My view is that semicompatibilists should give up these defenses and instead adopt symmetrical requirements on moral responsibility for actions and omissions, and in this paper I highlight three advantages of doing so: first, it avoids a strange implication of the truth of determinism; second, it allows for a principled reply to Philip Swenson's recent 'No Principled Difference Argument'; third, it provides a reason to reject a crucial inference rule invoked by Peter van Inwagen's 'Direct Argument' for the incompatibility of moral responsibility and determinism.
\end{abstract}

Keywords moral responsibility, semicompatibilism, asymmetry thesis, determinism, No Principled Difference Argument, Direct Argument

\section{Introduction}

Semicompatibilists believe that the freedom required for moral responsibility is compatible with causal determinism even if the ability (or freedom) to do otherwise is not. ${ }^{1}$ In fact, these theorists reject the following principle:

Principle of Alternative Possibilities (PAP): A person is responsible for performing an action only if they could have done otherwise than perform that action.

To support their rejection of this principle, semicompatibilists typically invoke 'Frankfurt-style cases', which are named after Harry Frankfurt because of his very influential paper [Frankfurt 1969]. In that paper, Frankfurt presented a case very similar to this one:

\footnotetext{
${ }^{1}$ Semicompatibilists are also sometimes called 'actual-sequence compatibilists' or 'Frankfurtstyle compatibilists'. Hereafter I use 'responsibility' as shorthand for 'moral responsibility' (and likewise for cognates).
} 
Frankfurt-Style Case (FSC): Black wishes Jones to cast his vote for presidential candidate A. In order to ensure that Jones does this, he implants a chip in Jones's brain which allows him to control Jones's behavior in the voting booth. (Jones has no idea about any of this.) Black prefers that Jones vote for candidate A on his own. But if Jones starts to become inclined to vote for anyone other than A, Black will immediately use his chip to cause Jones to vote for candidate A instead. As it turns out, though, Jones votes for candidate A on his own and Back never exerts any causal influence on Jones's behavior. [Swenson 2015: 1279-80]

In this case, Jones is apparently responsible for voting for candidate A. Yet Jones cannot do otherwise than vote for candidate A. Thus, PAP appears to be false.

But now consider a case in which an agent omits to perform an action that he is unable to perform:

Sharks: John is walking along the beach and sees a child drowning in the water. John believes that he could rescue the child without much effort. Due to his laziness, he decides not to attempt to rescue the child. The child drowns. Unbeknownst to John, there is a school of sharks hidden beneath the water. If John had attempted to rescue the child, the sharks would have eaten him and his rescue attempt would have been unsuccessful. [Swenson 2015: 1280; originally from Fischer and Ravizza 1998: 125]

In this case, John omits to rescue the child from drowning, yet John does not appear to be responsible for this omission because of the presence of the sharks. Even if PAP is false, then, the following principle looks very plausible: 
Principle of Possible Action (PPA): A person is responsible for omitting to perform an action only if they could have performed that action. ${ }^{2}$

Since the Sharks case seems to show that an agent cannot be responsible for omitting to perform an action that they are unable to perform, this case appears to support PPA.

Although they are motivated by cases like FSC to reject PAP, semicompatibilists have not wanted to give up PPA, and so they have defended asymmetrical requirements on responsibility for actions, on the one hand, and responsibility for omissions, on the other hand. In other words, they accept the following thesis:

Asymmetry Thesis (AT): PAP is false, but PPA is true. ${ }^{3}$

In other work [Cyr 2017], I have argued that AT is untenable and that recent modifications of AT by semicompatibilists like John Martin Fischer [2017] and Carolina Sartorio [2005] are problematic as well. Since semicompatibilists are committed to rejecting PAP, and since PPA is a very attractive principle, one might take my argument against AT as an objection to semicompatibilism. But, of course, semicompatibilists have an alternative, namely to give up PPA and to accept symmetrical requirements on responsibility for actions and omissions.

In this paper, I present three advantages (for semicompatibilists) of adopting symmetrical requirements on responsibility for actions and omissions. The first is simplest, and it is that

\footnotetext{
${ }^{2}$ For a discussion of this and related principles, see van Inwagen [1978].

${ }^{3}$ Not all semicompatibilists have stated their view in exactly this way. Fischer [1985-1986] and Fischer and Ravizza [1991] did defend AT, but Fischer has been convinced - partly because of Frankfurt's [1994] reply — that the simple version of AT is false. Fischer and Ravizza [1998] argue that what matters is whether or not some state of affairs is sensitive to an agent's actions, which does not seem equivalent to AT. Nevertheless, Fischer and Ravizza's view does imply an asymmetry between action cases and (certain) omission cases, even if their view is not motivated primarily by reflection on FSC and Sharks. Interestingly, Fischer's most recent view [Fischer 2017], which is closer to AT than the view that he has defended in the meantime, is developed in response to Swenson's [2015] argument that I will address later in the paper.
} 
adopting a symmetrical account avoids a strange implication of the truth of determinism. As noted above, semicompatibilists are open to the possibility that determinism precludes the ability to do otherwise. If so, and if PAP is false but PPA true, then agents in deterministic worlds can be responsible for their actions but not for their omissions. I argue that semicompatibilists should not countenance such a result.

The second reason to adopt a symmetrical account is that it allows for a principled reply to Philip Swenson's [2015; 2016] recent 'No Principled Difference Argument' against semicompatibilism. According to Swenson, since there is no principled difference between a series of cases that begins with Sharks and ends with a case like FSC, and since it is intuitive that the agent is not responsible for the relevant omission in Sharks, we should infer that the agent is not responsible for the relevant action in FSC. Rather than denying any of Swenson's plausible 'no relevant difference' claims, as an asymmetrical approach must, my symmetrical approach accepts these claims but maintains that the agent in Sharks is responsible for his omission. This is a prima facie counterintuitive position, though, so I go on to provide an error theory for the attraction of alternative replies.

Third and finally, a symmetrical account provides a reason to reject a crucial inference rule invoked by Peter van Inwagen's [1983] 'Direct Argument' for the incompatibility of responsibility and determinism. According to van Inwagen's 'Rule A', no one is responsible for necessary truths. But once it is granted that one can be responsible for an omission without having the ability to perform the omitted action, we can generate cases in which an agent is responsible for omitting to perform an action that they necessarily did not perform, and thus these cases constitute counterexamples to Rule A. This too may seem, prima facie, to be a counterintuitive position, yet the very same resources invoked in my error theory for the 
attraction of alternative replies to Swenson's argument will help us to see that denying Rule A is not as problematic as it initially seems.

While I hope to show the advantages for semicompatibilists of adopting symmetrical requirements on responsibility for actions and omissions, it is not the aim of this paper to provide a complete semicompatibilist account here. It is worth mentioning, though, that the semicompatibilist has various options. One is to opt for a hierarchal form of compatibilism, such as Frankfurt's [1988] own view, instead of appealing to reasons-responsiveness, as Fischer and others have wanted to do. Another option is to keep an agent's reasons front-and-center but to reject accounts of reasons-responsiveness that imply asymmetrical requirements on responsibility for actions and omissions. One view along these lines would be that, so long as an agent succeeds in bringing about the action/omission that the agent intended, the agent may be responsible even if the action/omission was inevitable. Of course, much more would need to be said about how to develop either of these sketches into a full-fledged semicompatibilism with symmetrical requirements on responsibility for actions and omissions, but the point of this paper is simply to motivate such a project.

\section{The Threat from Determinism}

Arguably the biggest challenge to compatibilism is the Consequence Argument, which was made popular by Peter van Inwagen [1983] and can be sketched as follows: If determinism is true, then propositions describing all of our actions are entailed by propositions expressing the laws of nature and propositions about the intrinsic state of the world long before we existed. In order for us to have the ability to do otherwise than what we in fact do, then, we would need to have a choice about either the laws of nature or the intrinsic state of the world in the distant past. 
But no one has a choice about those things, so, if determinism is true, we lack the ability to do otherwise than we what we actually do.

One putative asset of semicompatibilism is that it is consistent with the soundness of the Consequence Argument. After all, if some case like FSC is successful, then we may be responsible despite lacking the ability to do otherwise, and so responsibility may be compatible with determinism even if the ability to do otherwise isn't. ${ }^{4}$ Given the force of the Consequence Argument, being able to accept its soundness gives semicompatibilism a considerable advantage over classical compatibilism - the view that responsibility requires the ability to do otherwise and that this ability is compatible with determinism.

But now suppose, as I am inclined to believe, that the Consequence Argument is indeed sound. Suppose also, as semicompatibilists have claimed, that there are asymmetrical requirements on responsibility for actions, on the one hand, and omissions, on the other. It follows that, if determinism is true, we are only ever responsible for our actions and never for our omissions. After all, given the soundness of the Consequence Argument, determinism would preclude not only the ability to do otherwise than what we do but also the ability to do what we omit to do. If responsibility for an omission requires the ability to perform the omitted action, as PPA maintains, then (assuming the soundness of the Consequence Argument) determinism would preclude responsibility for omissions.

Semicompatibilists should not countenance the result that we may be responsible for our actions but not (any of) our omissions. As Randolph Clarke points out:

\footnotetext{
${ }^{4}$ Of course, as Fischer has always been careful to point out [cf. Fischer 1982], compatibilism about responsibility and determinism doesn't follow straightaway from the success of some case like FSC. It could be that responsibility and determinism are incompatible for some other reason than that determinism precludes the ability to do otherwise.
} 
If we're morally responsible for anything, omitting and refraining are among the things for which we're responsible. One might be blameworthy for failing to keep a promise, or praiseworthy for holding one's tongue. There can be criminal responsibility as well; the parents might be guilty of manslaughter for not doing something that, as parents, they had a legal duty to do. [2014: 1-2]

Moreover, Clarke continues, 'Like acting, omitting and refraining reflect on us as moral agents. They show what we care about, and sometimes what we don't care enough about' [2014: 2]. A view that admits the possibility that we are responsible for actions but never for omissions fails to take seriously the centrality of omissions to morality, to the law, and to our relationships with each other.

Some semicompatibilists (most notably Fischer) take care to ensure that their theories do not imply that aspects of our view of ourselves as responsible agents depend on whether or not determinism is true. It would be a mistake for our self-conception to 'hang by a thread' in this way. For example, Fischer says that 'our basic status as distinctively free and morally responsible agents should not depend on the arcane ruminations — and deliverances—of the theoretical physicists and cosmologists' [2006: 5; cf. Fischer and Ravizza 1998: 16]. While our status as free and responsible agents does not completely depend on our being responsible for omissions (since we would still be free and responsible agents even if we were only ever responsible for actions), given the centrality of omissions to morality, to the law, and to our interpersonal relationships, anyone motivated by this point about the 'resiliency' of our selfimage should be motivated to preserve our responsibility for omissions too, not leaving this to 'hang by a thread' from which responsibility for actions does not hang. 
As I noted above, Fischer no longer accepts the simple asymmetrical view (AT) that PAP is false but PPA true. Fischer now accepts the following:

Fischer's New Asymmetry Thesis (FNAT): responsibility for actions and simple omissions does not require freedom to do otherwise, whereas responsibility for complex omissions does require such freedom. [cf. Fischer 2017: 156]

FNAT appeals to the distinction between simple omissions and complex omissions. The former are 'identical to, or fully constituted by, a bodily movement, where this can include the body's keeping still (or a part of the body's keeping still)' [Fischer 2017: 156]. A complex omission, by contrast, 'is not identical to or fully constituted by (say) keeping my body still; it involves something more than the body—something about the relationship between the body and the external world' [Fischer 2017: 156]. Returning to some of Clarke's examples of omissions, holding one's tongue is an example of a simple omission, since it is identical to (or constituted by) keeping one's body perfectly still, whereas a case of manslaughter by omitting to feed one's child is a complex omission, since it involves something more than the parent's body. According to FNAT, the requirements on responsibility for simple omissions are symmetrical to those on responsibility for actions (that is, they do not require the ability to do otherwise), but the requirements on responsibility for complex omissions are different. Responsibility for complex omissions requires the ability to perform the omitted action.

Now, suppose again that the Consequence Argument is sound and that we discover that our world is deterministic. It follows, according to FNAT, that we are only ever responsible for our actions and simple omissions but never for our complex omissions. But notice that it is not only simple omissions but also complex omissions that are central to morality, to the law, and to our interpersonal relationships. Besides omitting to feed one's child, examples of complex 
omissions include omitting to keep one's promise to pick up a friend from the airport, omitting to vote for the most qualified candidate for a position, omitting to come to a complete stop at a stop sign, etc. Even if FNAT allows that we are responsible for our simple omissions on the assumption of determinism, the fact that it rules out responsibility for complex omissions on this assumption is just as problematic as the original asymmetrical view. ${ }^{5}$

Given that semicompatibilists are open to the possibility that the Consequence Argument is sound and determinism true, adopting asymmetrical requirements on responsibility for actions and omissions commits them to a strange picture of what we may be responsible for-a picture that, I believe, is at odds with our self-image. Since this strange implication can be avoided by adopting a symmetrical account of the conditions on responsibility, semicompatibilists have at least some reason for doing so.

\section{Swenson's 'No Principled Difference Argument'}

Swenson has recently presented a challenge to semicompatibilists by identifying a tension in our judgments that agents in cases like FSC are responsible, on the one hand, and our

\footnotetext{
${ }^{5}$ As an associate editor for this journal has pointed out to me, perhaps someone like Fischer could respond to this point by claiming that our responsibility for complex omissions can be entirely explained by our responsibility for simple omissions that are essential elements in the causal chain leading to a complex omission. I am skeptical, though, that responsibility for all complex omissions can be derived from responsibility for simple omissions (and actions) for three reasons. First, it is not obvious what the relevant simple omissions (and actions) would be in typical cases of significant complex omissions like the case of manslaughter by omitting to feed one's child. Some candidates may include, say, eating all of the remaining food in the house on Sunday, or omitting to decide to feed the child on Monday morning. But, and here is a second worry, it is not clear that the parent's responsibility for actions and simple omissions like these would add up to responsibility for manslaughter. Finally, setting aside these first two worries, this type of response would require the view that an agent's responsibility for a complex omission can be 'traced' back to the agent's responsibility for something else, and it remains a matter of dispute whether there can be a satisfactory account of tracing — see, e.g., Vargas [2005] and Fischer and Tognazzini [2009].
} 
judgments that agents in cases like Sharks are not responsible, on the other hand. The argument, as Swenson presents it, relies on a series of cases, each of which, Swenson claims, are not relevantly different from each other. Before we can consider the argument, though, we need to have the remaining cases before us. Swenson begins with Sharks and then provides three additional cases and argues that there is no relevant difference between them with respect to John's responsibility. Here are the three cases:

Penned-in Sharks: Everything occurs just as in Sharks except for the fact that the sharks are penned up. However, unbeknownst to John, there is an evil observer who wishes for the child to drown. If John had jumped into the water, the evil observer would have released the sharks, and as a result, the sharks would still have prevented John from rescuing the child. But the presence of the observer plays no role in the actual sequence of events. [2015: 1281]

Sloth: In this case, there are no sharks present to prevent a rescue by John. The evil observer is now monitoring John's thoughts instead. John decides (without deliberating much) to refrain from saving the child. If John had seriously considered attempting to rescue the child, the evil observer would have caused him to experience an irresistible urge to refrain from saving the child. However, this observer still plays no role in causing John's decision to refrain from attempting a rescue. [2015: 1281 $]^{7}$

Hero: John decides (without deliberating much) to rescue the child, and he successfully does so. Unbeknownst to him, if he had seriously considered refrain[ing] from rescuing

\footnotetext{
${ }^{6}$ Cf. Fischer and Ravizza [1998: 138], who credit David Kaplan for suggesting the case.

${ }^{7}$ Cf. Frankfurt [1994].
} 
the child, our now benevolent observer would have caused him to immediately experience an irresistible urge to rescue the child. [2015: 1282] ${ }^{8}$

Now that all of Swenson's cases are on the table, we can consider his argument:

(P1) In Sharks John is not responsible for failing to save the child.

(P2) If John is not responsible for failing to save the child in Sharks, then he is not responsible for failing to save the child in Penned-in Sharks.

(P3) If John is not responsible for failing to save the child in Penned-in Sharks, then he is not responsible for failing to save the child in Sloth.

(P4) If John is not responsible for failing to save the child in Sloth, then he is not responsible for saving the child in Hero.

Thus;

(Conclusion) John is not responsible for saving the child in Hero. [2015: 1282]

And since Hero is structurally identical to FSC, Swenson says, 'the cogency of this argument gives us reason to doubt that Jones is responsible for voting as he does' [2015: 1282]. Not only does this count against one of the semicompatibilist's core commitments (that there is some successful case like FSC), but, Swenson argues, there is a general (and in principle) reason to doubt that semicompatibilists will be able successfully to respond to his argument. I will return to this general reason later on.

In the next section, I will argue that adopting a symmetrical account of the conditions on responsibility for actions and omissions provides semicompatibilists with a principled reason for granting that John is responsible in all of Swenson's cases, including Sharks. Now, almost everyone who has written about Sharks has agreed that John is not responsible for his omission

${ }^{8}$ Cf. Fischer and Ravizza [1991]. 
in this case. In section 5, I will provide an error theory for the attraction of denying John's responsibility in Sharks, but it is also worth noting that Florian Cova [2017] has discovered that people's intuitions about Sharks are actually quite mixed. ${ }^{9}$ It may turn out, then, that we have independent reason to reject the non-responsibility intuition in Sharks and to accept the agent's responsibility in FSC.

\section{Answering the 'No Principled Difference Argument'}

I want to suggest a new type of response to Swenson's argument (one that Swenson [2015] ignores but is briefly addressed at the end of Swenson [2016]) according to which John is responsible for failing to save the child in Sharks, and according to which he is responsible in the remainder of the cases as well, since there is no responsibility-relevant difference between the cases. In other words, it is open to semicompatibilists to grant Swenson his series of no-relevantdifference claims, which appear in (P2)-(P4), but to start with Hero (or FSC), in which John is intuitively responsible, and to work backward from there, using the contrapositives of (P2)-(P4), to establish John's responsibility in Sharks. In (still) other words, Swenson's modus ponens may be the semicompatibilist's modus tollens. Below is a 'Modified No Principled Difference Argument':

(P1*) In Hero John is responsible for saving the child.

$\left(\mathrm{P} 2^{*}\right)$ If John is responsible for saving the child in Hero, then he is responsible for failing to save the child in Sloth.

\footnotetext{
${ }^{9}$ Thanks to two anonymous referees for pointing out this additional support for the view I am defending.
} 
(P3*) If John is responsible for failing to save the child in Sloth, then he is responsible for failing to save the child in Penned-in Sharks.

(P4*) If John is responsible for failing to save the child in Penned-in Sharks, then he is responsible for failing to save the child in Sharks.

Thus;

(Conclusion*) John is responsible for failing to save the child in Sharks.

Since Hero is structurally identical to FSC, the cogency of the argument provides semicompatibilists (who were antecedently committed to the success of cases like FSC to falsify PAP) with a reason to take John to be responsible for failing to save the child in Sharks.

The response I am suggesting on behalf of semicompatibilists is structurally parallel to the so-called 'hard-line reply' to the Manipulation Argument against compatibilism. ${ }^{10}$ The Manipulation Argument attempts to show that ordinary agents in deterministic worlds are not relevantly different from manipulated agents whom we intuitively judge not to be responsible. After presenting a case in which an agent is manipulated into performing some action from some compatibilist-friendly agential structure (CAS), the Manipulation Argument proceeds in the following form:

1. If $\mathrm{S}$ is manipulated in manner $\mathrm{X}$ to $\mathrm{A}$, then $\mathrm{S}$ does not $\mathrm{A}$ of their own free will and is therefore not responsible for A'ing.

2. An agent manipulated in manner $\mathrm{X}$ to $\mathrm{A}$ is no different in any relevant respect from any normally functioning agent determined to do A from CAS.

\footnotetext{
${ }^{10}$ For a widely discussed version of the Manipulation Argument, see Pereboom [2001: 110-117]. For a 'hard-line reply' to this argument, see McKenna [2008]. I follow McKenna's presentation of the manipulation argument in what follows.
} 
3. Therefore, if $\mathrm{S}$ is a normally functioning agent determined to A from CAS, S does not A of their own free will and therefore is not responsible for A'ing. ${ }^{11}$

Now, a compatibilist advancing the hard-line reply to the Manipulation Argument admits the truth of the second premise (that there is no relevant different between ordinary determined agents and certain manipulated agents) but denies the non-responsibility of ordinary determined agents and thus also denies the non-responsibility of certain manipulated agents.

Just as the hard-line reply to the Manipulation Argument denies the conclusion of that argument while granting the no-relevant-difference claim, my hard-line reply to Swenson's No Principled Difference Argument is to deny the conclusion of that argument while granting the no-relevant-difference claim. Instead of taking a 'soft-line' approach to Swenson's cases, attempting to point out a relevant difference between Sharks and Penned-in Sharks (or some other pair of cases), ${ }^{12}$ a semicompatibilist can grant Swenson that there is not a relevant difference between the cases without accepting that agents in cases like FSC (hereafter 'FSCs') lack responsibility. Since the semicompatibilist antecedently judges agents in FSCs to be responsible, they can take the hard-line approach, codified in the Modified No Principled Difference Argument, and infer that the agent in Sharks is responsible for his omission. ${ }^{13}$

To be sure, Swenson and others will think that starting with the judgment that the agents in FSCs are responsible is problematic, since it leads the hard-liner to conclude that the agent in

\footnotetext{
${ }^{11}$ See McKenna [2008: 143].

${ }^{12}$ For soft-line replies, see Byrd [2007], Clarke [1994; 2011], Fischer and Ravizza [1998: 140141], and Sartorio [2011]. See Swenson [2016] for objections.

${ }^{13}$ For another route to the same 'hard-liner' position, see Kearns [2011], who notes that cases like Sharks are not relevantly different from Locke's famous example of the man in the locked room [cf. Locke 1690 (1975), book 2, Chap. 21, Sect. 10]. Kearns's cases are also relevant to Rule A of van Inwagen's Direct Argument, which we'll return to below.
} 
Sharks is responsible. But the judgment that agents in FSCs are responsible is widespread, and not just among semicompatibilists. ${ }^{14}$ (Additionally, as noted above, people's responses to Sharks are quite mixed.) For those of us convinced of Swenson's no-relevant-difference claims, it will matter which case we take as our starting point, and Swenson has not shown there to be anything problematic about denying what one might have initially judged plausible about Sharks, given the initial plausibility of FSCs and given Swenson's no-relevant-difference point.

\section{An Error Theory for the Attraction of a Soft-Line Reply}

Given the simplicity of a hard-line reply to the No Principled Difference Argument, one may wonder why semicompatibilists have been so eager to show that there is a difference between FSCs and cases like Sharks. In what follows, I sketch a possible error theory for the widespread attempts at accommodating John's lack of responsibility in Sharks. ${ }^{15}$ As it happens, the resources invoked in this error theory will also be relevant to my discussion of giving up Rule A later on.

Cases in which agents fail to be responsible for omissions when they could not have succeeded in doing otherwise are ubiquitous. Consider the following case:

Burglary: While John is at the bank, a group of men (who intend to rob the bank) begin pointing guns at everyone in the bank, threatening them not to move. Very close to John is a button labeled 'Press In Case Of Emergency'. If John were to press the button, the police would be notified and the burglary would be thwarted. Because he is held at gun-

\footnotetext{
${ }^{14}$ For examples of incompatibilists who are convinced that agents in FSCs are responsible, see Stump [1996], Hunt [2000], and Pereboom [2003].

15 This error theory parallels McKenna's suggested explanation for our intuitions about certain manipulated agents. See McKenna [2008: 156-158].
} 
point, however, John is unable to thwart the burglary, and the burglars succeed in robbing the bank.

In Burglary, not only is it clear that John is not responsible for omitting to thwart the burglary, but it is clear that the factors which made it the case that John could not have succeeded in thwarting the burglary also played a causal role in his omitting to thwart the burglary. Such cases are the basis for legitimate 'I couldn't help it!' claims, for we take it that the agent's inability to do the thing in question actually played a role in preventing her from doing it.

Since cases like Burglary are quite common, it should not be surprising that in similar but relevantly different cases, namely those in which the agent's inability to do the thing in question does not actually play a role in preventing her from doing it, we find ourselves with the intuition that the agents are not responsible for their omissions. ${ }^{16}$ Our intuitions about cases of responsibility for omissions depend, to some extent, on the ordinary and common cases like Burglary, cases in which the agents' inabilities to perform certain actions constitute genuine excuses for their not performing them, and on our typical practice of excusing agents in them. When we shift to a case like Sharks, we find that, when we consider the presence of the Sharks and the counterfactual scenario in which John attempts to save the child but fails, we have the same intuition about this case as about the ordinary cases in which the factors preventing the relevant action from possibly occurring also prevent it from actually occurring. But the sharks do not play a role in John's failure to save the child, while the men holding John down in Burglary do play a role in his failure to thwart the burglary. ${ }^{17}$

\footnotetext{
${ }^{16}$ Frankfurt [1969] makes a similar claim about responsibility for actions and the intuitive appeal of PAP.

${ }^{17}$ Similarly, as I will discuss below, the factors which bring it about that only one action is possible for an agent in FSCs do not also play a role in that action's actual occurrence.
} 
Near the end of his classic article, Frankfurt remarked that agents in FSCs could not (without being disingenuous) offer certain excuses for what they had done:

We often do, to be sure, excuse people for what they have done when they tell us (and we believe them) that they could not have done otherwise. But this is because we assume that what they tell us serves to explain why they did what they did. We take it for granted that they are not being disingenuous, as a person would be who cited as an excuse for the fact that he could not have avoided doing what he did but who knew full well that it was not at all because of this that he did it. [1969: 837-838]

I agree with Frankfurt's explanation of why agents in FSCs could not offer as an excuse that they could not have done otherwise, but I see no reason to think that similar considerations do not apply in omission cases like Sharks. ${ }^{18}$ Suppose that John omits to save the child and later discovers that sharks had been present. And suppose that, when approached by the child's parent, John says that he could not have done otherwise than omit to save the child. Clearly it would be a moral failing of John to cite the sharks' presence as an excuse for what he failed to do; he knew full well, as Frankfurt says, that it was not at all because of this that he did it. ${ }^{19}$

\footnotetext{
${ }^{18}$ Nor do I think Frankfurt would disagree with applying these considerations to cases involving omissions. As he points out, 'There appears to be no fundamental reason why instances of performing actions should be, as such, morally different from instances of not performing them. After all, the distinction between actions and omissions is not a very deep one' [1994: 620].

${ }^{19}$ In more recent work [Swenson Forthcoming], Swenson offers an alternative explanation for the failure of this sort of excuse. Building on work on by Fischer [1985-1986] and Zimmerman [2002], Swenson claims that John (in Sharks) is just as blameworthy as he would have been had the sharks not been present, but he also claims that the scope of what John is blameworthy for shrinks when the sharks are present. If this is right, then perhaps John's excuse fails because it does not reduce John's degree of blameworthiness, and a successful excuse reduces an agent's degree of blameworthiness. I do not have space to give a complete assessment of this alternative here, but, because I do not think Swenson's scope/degree response to moral luck is successful (for reasons I plan to develop in future work), I do not think this alternative explanation for the failure of John's excuse will be ultimately successful either.
} 
In cases like Burglary, however, it would be perfectly appropriate for John to offer as an excuse the fact that he was unable to thwart the burglary. The reason for this is that the factors that make it inevitable that John omits to thwart the burglary also play a causal role in his failing to thwart the burglary. And, as Frankfurt noted, it is precisely because the factors that make an agent's action inevitable in FSCs do not play a causal role in the bringing about the agent's action that the agent is apparently responsible (and thus that the case serves as a counterexample to PAP):

[T] here may be circumstances that constitute sufficient conditions for a certain action to be performed by someone and that therefore make it impossible for the person to do otherwise, but that do not actually impel the person or in any way produce his action. A person may do something in circumstances that leave him no alternative to doing it, without these circumstances actually moving him or leading him to do it—without them playing any role, indeed, in bringing it about that he does what he does. [1969: 830] ${ }^{20}$ Crucially, the factors at play in FSCs that constitute sufficient conditions for the agent's action do not play a causal role in the production of his action.

As it happens, it is precisely these considerations which Swenson takes to give rise to a general reason to doubt that semicompatibilists can successfully to respond to his argument. Swenson notes that Fischer has helpfully distinguished between the factors of a situation which bring about a particular event, which Fischer dubs the 'A-Factors', and the factors which render the event inevitable but need not cause or bring about the event, which he dubs the 'B-Factors'. ${ }^{21}$ The lesson to be learned from the FSCs, then, is that mere B-Factors (which are not also A-

\footnotetext{
${ }^{20}$ Part of this quotation is cited by Swenson [2015: 1283].

${ }^{21}$ Cf. Fischer [2010: 269], cited by Swenson [2015: 1283].
} 
Factors) are not relevant to agents' responsibility. (In Frankfurt's terminology: circumstances that constitute sufficient conditions for a certain action to be performed need not actually impel the person or in any way produce his action.) But Swenson argues that this lesson provides an in principle reason to doubt that a reply to the No Principled Difference Argument will be successful:

This reveals an additional challenge for anyone who wishes to reply to the no principled difference argument. The problem is that each case appealed to in the no principled difference argument centrally involves the presence of a mere B-Factor (the sharks in Sharks, the evil observer in Penned-in Sharks, etc.). Furthermore, accepting that the agent is not responsible in any of the cases apparently involves rejecting the claim that mere BFactors are always irrelevant to moral responsibility. Frankfurt-Style Compatibilists (and any other defenders of FSCs) should say that the principle underlying our intuitions about FSCs is correct. So they should not accept the claim that John is not responsible in any of the cases appealed to in the no principled difference argument. Thus, they cannot plausibly draw a line anywhere between Sharks and Hero with regard to John's responsibility. [2015: 1284]

Swenson's argument puts pressure on the semicompatibilist to give consistent responses to the various cases we have considered, and he thinks that this is an in principle reason to doubt that a reply to his argument will be successful. But notice that the considerations to which Swenson appeals provide equal support for the hard-line reply that I have developed here. The fact that semicompatibilists (who have the intuition that John is responsible in Hero) have reason to doubt that they can plausibly draw a line anywhere between Sharks and Hero should motivate them to adopt the hard-line reply to the No Principled Difference Argument. And taking this hard-line 
reply and granting the responsibility of John in Sharks is a live option for the semicompatibilist who adopts symmetrical requirements on responsibility for actions and omissions.

\section{Van Inwagen's 'Direct Argument'}

The third benefit (to semicompatibilists) of adopting a symmetrical account of the requirements on responsibility for actions and omissions is that it allows for a response to van Inwagen's [1983: 182-188] Direct Argument. The Direct Argument is structurally similar to the Consequence Argument—-sketched in section 2 above_- but argues for the incompatibility of determinism and responsibility directly (instead of arguing that determinism precludes the ability to do otherwise, and then relying on a principle like PAP to get to a conclusion about responsibility). This argument relies on two inference rules that govern a 'no-responsibility' operator. Let 'NRp' abbreviate ' $p$, and no one is even partly responsible for the fact that $p$.' The

first rule, Rule A, says that if $p$ is broadly logically necessary, then NRp. More formally:

$$
\text { A. } \square p \vdash \mathrm{NR} p
$$

The second rule, Rule B, says that if no one is even partly responsible for the fact that $p$ entails $q$, and if no one is even partly responsible for the fact that $p$, then no one is even partly responsible for the fact that $q$. More formally:

$$
\text { B. } \mathrm{NR}(p \supset q), \mathrm{NR} p \vdash \mathrm{NR} q \text {. }
$$

Now, let ' $\mathrm{P}_{0}$ ' stand for a proposition describing the intrinsic state of the world in the distant past, let ' $\mathrm{L}$ ' stand for the conjunction of the laws of nature, and let ' $\mathrm{P}$ ' stand for any true sentence. Van Inwagen argues as follows (here I'm following the presentation in Capes [2016: 1479]):

0. Determinism is true

1. $\square\left(\left(\mathrm{P}_{0} \& \mathrm{~L}\right) \supset \mathrm{P}\right)$ assumption for conditional proof

formal consequence of 0 
2. $\square\left(\mathrm{P}_{0} \supset(\mathrm{L} \supset \mathrm{P})\right) \quad$ from 1

3. NR $\left(\mathrm{P}_{0} \supset(\mathrm{L} \supset \mathrm{P})\right) \quad$ from 2 by Rule $\mathrm{A}$

4. NR $\mathrm{P}_{0} \quad$ premise

5. NR $(\mathrm{L} \supset \mathrm{P}) \quad$ from 3 and 4 by Rule $\mathrm{B}$

6. NR L premise

7. NR P from 5 and 6 by Rule B

8. Determinism is true $\supset$ NR P conditional proof

Since we used ' $\mathrm{P}$ ' as an abbreviation for any true sentence, it follows from this conclusion that, if determinism is true, then no one is even partly responsible for the fact that they perform their actions.

Now, the most popular response to the Direct Argument has been to attempt to provide counterexamples to Rule B — examples in which an agent appears responsible for an outcome even though that outcome is overdetermined. As Justin Capes has recently argued, however, counterexamples to Rule B do not falsify a related inference rule, 'Transfer NR*' (a modified rule about the transfer of non-responsibility). According to Transfer NR*, 'if a person is not even partly morally responsible for any of the circumstances that led to a particular outcome, and if that person is not even partly morally responsible for the fact that those circumstances led to that particular outcome, then the person is not even partly morally responsible for the outcome in question either' [2016: 1484]. And since, as Capes convincingly shows, Transfer NR* can play the role Rule B originally played in the Direct Argument, the popular response that appeals to cases of overdetermination will ultimately fail as a response to the Direct Argument. ${ }^{22}$

${ }^{22}$ See Capes [2016: 1491] for the full presentation of the modified Direct Argument. 
Given that the popular attempts to falsify Rule B will not succeed in falsifying Capes's rule $\mathrm{B}^{*}$, it would be nice for semicompatibilists to have an alternative line of response to the Direct Argument (and to Capes's modified version of the argument). I will now argue that semicompatibilists can gain a principled reason for rejecting Rule A (and Capes's modified version of the rule — rule $\mathrm{A}^{*}$ — too) by adopting a symmetrical account of the requirements for responsibility for actions and omissions.

\section{Against Rule A}

Recall that, on the symmetrical view of responsibility for actions and omissions, an agent can be responsible for an omission even if the agent lacks the ability to perform the omitted action. If one accepts this view, one accepts the first premise of the following argument:

1) Agents can be responsible for the fact that they omit to do something that they were nonetheless unable to do

2) If agents can be responsible for the fact that they omit to do something that they were nonetheless unable to do, then agents can be responsible for facts that obtain necessarily

3) Agents can be responsible for facts that obtain necessarily ${ }^{23}$

The conclusion of this argument is the denial of Rule A of van Inwagen's Direct Argument (and also of rule A* of Capes's modified version of the argument). Provided that one accepts the second premise of my argument, adopting my approach to responsibility for omissions (and thus accepting the first premise of this argument) provides a principled reason for rejecting Rule A

\footnotetext{
${ }^{23}$ See Kearns [2011] and Hermes [2014] for different arguments for this same conclusion.
} 
and thus for denying the soundness of the Direct Argument. All that remains, then, is to determine the plausibility of the second premise of this argument.

In my view, this premise enjoys considerable intuitive plausibility. Moreover, to deny it would be to maintain that, while one can be responsible for the fact that one omitted to do what one was unable to do, one cannot be responsible for the fact that one necessarily omitted to perform a certain action. But what reason could there by for maintaining this conjunction of views? If one already accepts that agents like the one in the Sharks case can be responsible for failing to prevent some inevitable outcome, then one also accepts that an agent can be responsible for failing to prevent an outcome that was inevitable because of circumstances over which no one had any control. It would be implausible, I submit, to say that agents can be responsible for a fact about some inevitable state of affairs only when that fact is not broadly logically necessary but only necessary given some features of the circumstances over which no one has any control (for example, given the presence of the sharks in the Sharks case). If something's being broadly logically necessary is relevant to an agent's non-responsibility for that thing, it must be because being broadly logically necessary precludes an agent's control over that thing. But if it is admitted that an agent can be responsible for something that is necessary given some features of her circumstances over which they have no control, then there is no reason to think an agent could not be responsible for some broadly logically necessary fact.

Now, we are not typically responsible for facts that obtain necessarily, so one might reasonably ask, at this point, which sorts of necessary facts one could be responsible for. ${ }^{24}$ Recall Fischer's distinction between the factors of a situation which bring about a particular event (the A-Factors) and the factors which render the event inevitable but need not cause or bring about

\footnotetext{
${ }^{24}$ Thanks to an anonymous referee and associate editor for raising this question.
} 
the event (the B-Factors). The lesson semicompatibilists should take from FSCs is that mere BFactors are not relevant to an agent's responsibility. And just as I claim that the presence of the sharks in Sharks is a mere B-Factor (and thus irrelevant to an agent's responsibility), I submit that agent may be responsible for an event even if some necessary fact renders that event inevitable, whether the fact is physically, metaphysically, or even logically necessary. What matters is whether the fact is an A-Factor or a mere B-Factor, and provided that the agent is unaware of the necessary fact, the fact can be a mere B-Factor and thus will not undermine the agent's responsibility. Of course, if I know that it is a necessary truth that squares have four sides, then I can omit to prove that a particular square has three sides and cite the necessary truth as a reason I am not responsible for my omission (the fact is an A-Factor). But suppose that Smith believes he can prove that some necessarily false mathematical claim but decides not to. ${ }^{25}$ On my view, Smith may be responsible for his omission, as the necessity of his failure to prove the claim was a mere B-Factor.

I suspect that those inclined to reject the conclusion of the above argument will also be inclined to reject its first premise. After all, the first premise seems to be the easier target, and even many compatibilists have wanted to reject it (for example, taking a soft-line response to Swenson's argument). But here I have, in effect, argued for the plausibility of that premise (or at least for its plausibility given a certain reaction to FSCs), motivating it and defending it against a recent objection. I conclude that semicompatibilists are best served by adopting a symmetrical account of the requirements for responsibility for actions and omissions and reaping the rewards that come with adopting that account.

25 This case, suggested by an anonymous referee, is very similar to the one discussed by Kearns [2011: 316ff]. 


\section{Acknowledgements}

For helpful discussion and for comments on previous drafts of this paper, I would like to thank the members of my dissertation committee, John Fischer, Dana Nelkin, Michael Nelson, Derk Pereboom, and Eric Schwitzgebel, as well as Zac Bachman, Dave Beglin, Andrew Law, Meredith McFadden, Jonah Nagashima, Debbie Nelson, Jeremy Pober, Jared Smith, and Philip Swenson. Thanks also to two anonymous reviewers and an associate editor for this journal.

\section{REFERENCES}

Byrd, Jeremy 2007. Moral Responsibility and Omissions, Philosophical Quarterly 57/226: 5667.

Capes, Justin 2016. Incompatibilism and the Transfer of Non-Responsibility, Philosophical Studies 173/6: 1477-1495.

Clarke, Randolph 1994. Ability and Responsibility for Omissions, Philosophical Studies 73/2-3: 195-208.

Clarke, Randolph 2011. Omissions, Responsibility, and Symmetry, Philosophy and Phenomenological Research 82/3: 594-624.

Clarke, Randolph 2014. Omissions: Agency, Metaphysics, and Responsibility. New York: Oxford University Press.

Cova, Florian 2017. Frankfurt-Style Cases and the Explanation Condition for Moral Responsibility: A Reply to Swenson, Acta Analytica 32/4: 427-446.

Cyr, Taylor 2017. Moral Responsibility for Actions and Omissions: A New Challenge to the Asymmetry Thesis, Philosophical Studies 174/12: 3153-3161.

Fischer, John Martin 1982. Responsibility and Control, Journal of Philosophy 79/1: 24-40.

Fischer, John Martin 1985-1986. Responsibility and Failure, Proceedings of the Aristotelian Society 86: 251-270.

Fischer, John Martin 2010. Replies, Philosophy and Phenomenological Research 80/1: 267-278.

Fischer, John Martin 2017. Responsibility and Omissions, in The Ethics and Law of Omissions, eds. D.K. Nelkin and S. Rickelss, New York: Oxford University Press: 148-162.

Fischer, J.M. and M. Ravizza 1991. Responsibility and Inevitability, Ethics 101/2: 258-278.

Fischer, John Martin, and Mark Ravizza 1998. Responsibility and Control: A Theory of Moral Responsibility. Cambridge: Cambridge University Press.

Fischer, J.M. and N. Tognazzini 2009. The Truth about Tracing, Nous 43/3: 531-556.

Frankfurt, Harry 1969. Alternate Possibilities and Moral Responsibility, Journal of Philosophy 66/23: 829-839.

Frankfurt, Harry 1988. The Importance of What We Care About. Cambridge University Press.

Frankfurt, Harry 1994. An Alleged Asymmetry Between Actions and Omissions, Ethics 104/3: 620-623.

Hermes, Charles 2014. A Counterexample to A, Philosophia 42/2: 387-389.

Hunt, David 2000. Moral Responsibility and Unavoidable Action, Philosophical Studies 97/2: 195-227.

Kearns, Stephen 2011. Responsibility for Necessities, Philosophical Studies 155/2: 307-324. 
Locke, John 1690 (1975). An Essay Concerning Human Understanding, ed. P.H. Nidditch, Oxford: Oxford University Press.

McKenna, Michael 2008. A Hard-line Reply to Pereboom's Four-Case Manipulation Argument, Philosophy and Phenomenological Research 77/1: 142-159.

Pereboom, Derk 2001. Living Without. Free Will. Cambridge: Cambridge University Press.

Pereboom, Derk 2003. Source Incompatibilism and Alternative Possibilities, in Moral Responsibility and Alternative Possibilities: Essays on the Importance of Alternative Possibilities, eds. D. Widerker and M. McKenna, Burlington: Ashgate Publishing: 185199.

Sartorio, Carolina 2005. A New Asymmetry Between Action and Omissions, Nous 39/3: 460-82. Sartorio, Carolina 2011. Actuality and Responsibility, Mind 120/480: 1071-1097.

Stump, Eleonore 1996. Libertarian Freedom and the Principle of Alternate Possibilities, in Faith, Freedom, and Rationality: Philosophy of Religion Today, eds. D. Howard-Snyder and J. Jordan, Lanham, Md.: Rowman and Littlefield: 73-88.

Swenson, Philip 2015. A Challenge for Frankfurt-Style Compatibilists, Philosophical Studies 172/5: 1279-1285.

Swenson, Philip 2016. The Frankfurt Cases and Responsibility for Omissions, Philosophical Quarterly 66/264: 579-595.

Swenson, Philip Forthcoming. Luckily, We Are Only Responsible for What We Could Have Avoided, Midwest Studies in Philosophy.

van Inwagen, Peter 1978. Ability and Responsibility, Philosophical Review 87/2: 201-224.

van Inwagen, Peter 1983. An Essay on Free Will. Oxford: Oxford Clarendon Press.

Vargas, Manuel 2005. The Trouble with Tracing, Midwest Studies in Philosophy 29: 269-291.

Zimmerman, Michael 2002. Taking Luck Seriously, Journal of Philosophy 99/11: 553-576. 